\title{
TRANSACTIONS
}

OF THE

ROYAL AERONAUTICAL SOCIETY.

Edited for the Council by J. Laurence Pritchard, Associate Fellow.

No. 3.

\section{AERO-ENGINE EFFICIENCIES}

BY

A. H. GIBSON, D.Sc., M.Inst.C.E., M.I.Mech.E.

The University, Manchester.

PRICE FIVE SHILLINGS.

London :

Che Kayal Aleranautical Saciety. 


\section{Aero-Engine Efficiencies.}

A. H. GIBSON, D.Sc., M.Inst.C.E., M.I.Mech.E.

The University, Sranchester.

London :

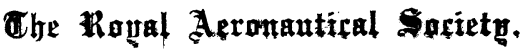

